\title{
The Health Gap. Doctors and the Social Determinants of Health
}

Michael Marmot

Institute of Health Equity

\section{Department of Epidemiology and Public Health, UCL}

\author{
Lecture given at NTNU, Trondheim, November 2016
}

Something odd happened to me. I have spent my whole professional life, saying that the key determinants of health, are not what happens in hospitals such as this. Health is determined not so much by what doctors do for patients, but by arrangements in society. The odd thing that happened, was that I became president of the World Medical Association, with a role of speaking to and on behalf of doctors. Given the position in which I found myself, I pursued the hypothesis that I could get doctors interested in health. I set the mission for my Presidency as encouraging doctors involvement in social determinants of health and health equity.

The first line of my book, The Health Gap, was: why treat people and send them back to the conditions that made them sick?(1) We need to treat people, but we need to address the issues that make people sick.

\section{The Social Gradient in Health}

Figure 1 is from the Marmot review of health inequalities in England, and it is reproduced in The Health Gap(2). The top graph is a plot of life expectancy. Each dot represents a neighbourhood in England, classified by degrees of affluence and deprivation. There is a remarkable social gradient. We are used to thinking that the poor have poor health; observers find that readily comprehensible. But why should people near the top have poorer health than those at the top? Why should people in the middle have poorer health than those at the top? The social gradient in health runs all the way from top to bottom of society. I first emphasised the gradient in health several decades ago, starting with the Whitehall Study.(3)

The bottom graph is disability-free life expectancy, and the gradient is steeper. The most affluent spend fewer years in disability. The most deprived have shorter lives, and spend more years of that shorter life with disability. The two plots also show that although health improved over the ten years from 1999-2003 to 2009-13 the slope of the gradient did not change. Inequality in health did not diminish.

We have to address the social gradient, not only the issue of poverty and health. Addressing the social gradient means addressing inequality across the whole of society. Americans commonly ask me why should I care about inequalities in health? I'm not poor, so I cannot be affected. The gradient in health is an insistent reminder that we should all care, even if only from self-interest. All of us below the very top are affected. A paper by Case \& Deaton, published in 2015, garnered a great deal of interest for precisely that reason.(4) Case and Deaton compared the USA with several other countries and showed that all-cause mortality in the 2 decades from 1990, for men and women aged 45-54, has been declining in France, Germany, U.K., Canada, Australia, Sweden, and in Hispanic Americans. But in US non-Hispanic whites, mortality has been rising. The failure of health to improve includes the average person, not just the poor. That said, the fewer the years of education, the steeper the rise. Hence the gradient is getting steeper. This rise in mortality cannot be attributed simply to lack of access to health care. The causes of death with the sharpest rise were, 
in order: poisonings due to drugs and alcohol, suicide, chronic liver disease largely alcohol-related. Then come violent deaths.

Examining those causes of death, all psychosocial, leads me to label this rise in mortality: disempowerment on a grand scale.

\section{Health inequalities vary across countries as well as over time}

A common question: if inequalities in health result from inequalities in society, aren't health inequalities inevitable? All societies have social inequalities; won't we then always have inequalities in health? Probably yes, but the magnitude varies The Case Deaton paper showed that health inequalities, by education, increased in the US i.e. in one society over time. The gradient in health also varies across societies. Figure 2 shows our comparison of life expectancy at 25 for men in different countries.(5) The differences were similar in direction in women, but smaller in magnitude. ISCED 0-2 is primary education, 5-6 is tertiary education. Sweden, Italy, Norway have the longest life expectancy at 25, and a narrow gap, a shallow gradient - the difference in life expectancy between those with primary education and those with tertiary education is relatively small. Estonia, Hungary, Romania, Bulgaria, Poland, i.e. the former communist countries of central-eastern Europe, have lower average life expectancy and huge gaps, a steeper gradient. Another way of saying this is that the between-country differences in life expectancy are much smaller for people with university education. They do know how to get good health in Estonia. People with university education get it, but the disadvantage of being lower in the hierarchy gets bigger as you go "east" (I include the Baltic states of the former Soviet Union as "east"). That is to say, the disadvantage of being low-status is still seen in Norway, but it is nowhere near as big as in Estonia, Hungary or Romania.

\section{Taking action: individual behaviour in social perspective}

For doctors interested in prevention, a standard approach is to give advice to patients on avoiding risky behaviours. A typical list would include advice about smoking, diet, exercise, alcohol, safe sex, protection from sun exposure, and perhaps road safety and taking advantage of opportunities for cancer screening.

The problem with such advice is that it is unlikely to change behaviour. The information in that list is widely known. People do not continue to smoke, for example, because of ignorance of the damaging health consequences but for a variety of psychological and social reasons. Simple advice will not work.

To see the limitations of such a list, here is an alternative list of top tips for health, compiled by David Gordon of the University of Bristol (http://www.bristol.ac.uk/poverty/healthinequalities.html):

1. Don't be poor. If you can, stop. If you can't, try not to be poor for long.

2. Don't live in a deprived area. If you do move.

3. Don't be disabled or have a disabled child.

4. Don't work in a stressful, low paid manual job.

5. Don't live in damp, low quality housing or be homeless.

6. Be able to afford to pay for social activities and annual holidays.

7. Don't be a lone parent.

8. Claim all benefits to which you are entitled.

9. Be able to afford to own a car.

10. Use education to improve your socio-economic position. 
The parody of the second list works because it is obvious that these influences on health are beyond the control of individuals. But so, in some measure, are individual behaviours in the first list. The whole point is that we need to address the social determinants of health. They may be the determinants of behaviours, and they may affect people's lives in other ways, damaging minds and bodies, that affect their health.

In relation to the first - determinants of behaviours - I talk about the 'causes of the causes'. We know that smoking is a potent cause of ill health, but even in a low-middle income country like India, the higher the wealth level, the lower the smoking. Smoking follows the gradient. We used to think that in rich countries, it was lower-income people that smoked, but in poor countries, it was higher-income people that smoke. Even in India now, we see the social gradient - lower social position, higher risk. Similarly with obesity, across Europe, we see the social gradient, more steeply in women than in men, but it is there in both genders.

Worryingly, social gradients in obesity are clear early in life. In Figure 3, we plot obesity in children aged 10-11 in England according to area of residence, classified on an index of multiple deprivation. The first thing to note is the remarkable social gradient: the greater the deprivation score, the greater the prevalence of obesity. Second, the time trends in obesity vary by level of deprivation. In the least deprived, for example, there has been no increase in obesity between 2006 and 2012-13. The rise in childhood obesity has stopped in children from higher-income families. By contrast, in children in more deprived areas the rise in obesity continues. As a result, inequalities in obesity are increasing. It is likely that childhood obesity will follow through into adulthood obesity. Figures up to 2015/2016 confirm this trend.

(http://www.content.digital.nhs.uk/catalogue/PUB22269/nati-chil-meas-prog-eng-2015-2016-rep.pdf).

If we want to solve the obesity problem, we have to solve the inequality problem. Addressing inequalities will take a broad set of social actions, such as those listed below. Even focussing more narrowly on food, we need to recognise that simply conveying the information that obesity is bad for health will be insufficient. Among the many factors influencing the social gradient in obesity are availability and price of different foods. Evidence shows that the density of fast food outlets follows the social gradient - the more deprived the area the greater the density of McDonalds, Burger King, KFC and Pizza Hut(6). Availability has to influence consumption. Purveyors of fast food might counter that they are only meeting demand. But demand must be related to the fact that such fast food is a relatively cheap form of calorie-dense food.

Consumption of fast food is indicative of wider social issues. In England, only $18 \%$ of people have one or more meals a day at their table(1). Only a third eat at their table once a week or more. One can imagine that if people are not eating at their table, they may be consuming ready meals in front of the television. Such patterns are deeply worrying. Quite apart from dietary patterns, not eating at table suggests less family interaction. Other figures show that the lower the family income the less parental input to early child development.

It is not just the UK that has an obesity problem. The global waistline is expanding. In Mexico, for example, just under $35 \%$ of women and $25 \%$ of men are obese - a BMI of 30 or greater. Consumption of sugar sweetened beverages may be an indicator of unhealthy diet, but may itself be a cause of obesity. Coca Cola publishes its sales by Region. Latin America is looking good for the company with sales high and rising. Mexico now leads the world: 675 servings (US 8oz) per person per year; nearly two a day for every adult 
and child. It is not fanciful to link high consumption of sugar-sweetened beverages to rampant obesity in Mexico.

\section{Action on Social Determinants of Health}

In my English review(2), and I lay out the evidence in "The Health Gap", I had six domains of recommendations of what we can do:

- Give every child the best start in life,

- education and life-long learning,

- $\quad$ employment and working conditions.

- $\quad$ everybody should have the minimum income necessary for a healthy life

- $\quad$ healthy and sustainable places to live and work,

- $\quad$ taking a 'causes of the causes' approach to prevention.

These all require action outside the health sector. My theme in this lecture is getting doctors involved. Is that possible?

\section{Getting the Doctors involved}

I chaired the Commission on Social Determinants of Health. On the cover of the report, Closing the Gap in a Generation, we said, social injustice is killing on a grand scale(7). In the report we had the best global evidence to inform policies on social determinants of health. When assuming the Presidency of the World Medical Association, my challenge to myself was to get doctors active on achieving health equity through action on social determinants of health. Following on from the Commission on Social Determinants of Health my two messages in a world of post-fact politics, were that we need evidence-based policy, and it needs to be presented in a spirit of social justice.

Supporting this mission, I had three aims for my year as president: to get a declaration on social determinants of health; to get national medical associations and doctors networking on the topic; and training.

\section{Declaration of Oslo and Doctors for Health Equity}

First, we got a Declaration of Oslo emphasising: the importance of social determinants of health; taking a life-course approach; addressing the causes of the causes; local and national action plans and what healthcare professionals can do. A recurrent question from doctors is along the lines of: I am convinced of the importance of social determinants of health, but what can I do? To answer that question we produced a report: Doctors for Health Equity. (http://www.instituteofhealthequity.org/Content/FileManager/wma-ihereport_-doctors-for-health-equity-2016.pdf) We identified five areas of action for doctors and national medical associations:

- workforce education and training,

- working with individuals and communities, seeing the patients in the broader perspective,

- the health sector as employers,

- working in partnerships,

- advocacy. 
This lecture is happening at a learning centre of an important university. Education and training needs to happen at every level. To support the effort, we produced a MOOC which ran in the autumn of 2016.

\section{Seeing the individual in a broader context}

On the second, working with individuals and communities and seeing the patient in a broader perspective, is part of the good practice of medicine. Paediatricians, for example, recognise the importance of wider issues on early child development beyond treating the sick child. In England, we have been monitoring the proportion of children age 5, who have a good level of development by deprivation of local authority, shown in figure 4 (https://www.instituteofhealthequity.org/projects/marmot-indicators-2015). The more affluent the local authority, the higher the proportion of children age 5, who have a good level of development. But there is scatter around the line. For a given level of deprivation, some areas are doing better than others.

I have suggested that this as a kind of litmus-test of political perceptions. People on the right say it's poor parenting, people on the left say it's poverty. And I say, they're both correct. In fact, the circumstances in which carers are trying to raise children impacts on early child development. Such impact sets life course trajectories: education, qualifications, the kind of job one has, the neighbourhood one lives in, income; all of which affect health, and health-inequalities. Discussion of Figure 4 suggests two approaches to reducing inequalities in early child development. One is to reduce poverty - bring the socioeconomic level of the most deprived communities up towards the average. The second is to become one of the communities above the line, that is doing better than the average for a given level of deprivation.

We have evidence that both can work. Nordic countries, in general, use the tax and benefit system to reduce child poverty. Other countries, less so. I have argued that the USA, for example, could achieve a dramatic reduction in child poverty if the US had as much redistribution as Australia.

On the second, there is good evidence that it is possible to break the link between poverty and poorer early child development. In England, one definition of poverty is children who are eligible for free school meals. As expected, children on free school meals (FSM) are less likely to have good level of development at age 5. They lag behind the average. What we find, though, is that the disadvantage of being a child in poverty (FSM) is less in deprived areas. This is illustrated in Figure 5.

On average, $60.4 \%$ of children in England are classified as having a good level of development at age 5. Among children eligible for free school-meals, $44.5 \%$ have a good level of development; the gap is 15.6. In Hackney, traditionally a poor part of east London but now rapidly gentrifying, I was told that they had broken the link between deprivation and poor early child development. The data bear this out. The gap is only four percent, between the FSM children and the average. In this post-fact universe aren't facts exciting! Much more exciting than some of the garbage politicians throw at us. We can make a difference in the world!

By contrast, look at Bath and North East Somerset, beautiful Georgian Bath: the gap between the FSM children and the average is large, nearly $30 \%$ difference in the proportion of children with a good level of development. My guess is if you go to Bath, and say what do you do for your poor children here? The response might be: poor children? Do we have many poor children here? It is not a major focus. But if 
you're not focusing on poor children in Hackney, what are you doing getting up in the morning? Because so many of the children are poor; it is a deprived part of London. The implication is clear: if you focus on the problem, you can solve it. This is terrific! Poverty is not destiny. It's rather bad, but it's not destiny.

\section{$\underline{\text { Health Sector as employer }}$}

I have highlighted conditions at work as contributors to the social gradient in health - chapter 6 in The Health Gap. There are, of course, persisting physical and chemical hazards that affect health workers, not to mention attacks on health workers in conflict zones, which are deeply reprehensible. Increasingly, the threats to health at work in the health sector are psychosocial, not just for doctors and nurses, but also for lab assistants, administrators, clerks, drivers, cleaners, and the like. We have highlighted two particular psychosocial measures at work, imbalance between effort and reward, and low control(8). Both of these show a social gradient: the lower the occupational class, the higher the likelihood of imbalance between effort and reward, and having low control at work. Both of those increase risk of cardiovascular disease, of mental illness, and sickness absence.

\section{Working in partnership}

It is easy to find accounts of Australian aboriginal health - strictly Aborigines and Torres Strait Islanders that are lacking in hope. The standard narrative is that \$billions have been spent, but aboriginal families are characterised by violence, alcohol, drugs, worklessness and high rates of crime.

Billions have been spent and aboriginal health is bad compared to the non-indigenous population -10.6 years shorter life expectancy for men and 9.4 years for women. But a different account says that when people's lives are characterised by betrayal of trust and systematic destruction of identity and self-worth leading to powerlessness perhaps it is no surprise that this Spiritual Sickness can lead to destructive behaviours. Money spent is not irrelevant. But the psychosocial issues are central. My starting position is that if communities and individuals are empowered it is more likely that money spent will lead to progress. But doctors cannot empower communities. There has to be partnership working.

I was in Australia in September 2016 to give a series of radio lectures for the Australian Broadcasting Commission: Fair Australia: Social Justice and the Health Gap

(http://www.abc.net.au/radionational/programs/boyerlectures/). The Australian Medical Association wrote to ask how could they help. I said I would like to see examples of doctors working in partnership on social determinants of health.

I was taken to an aboriginal community centre, the Tharawal Aboriginal Corporation, 50 kilometres south of Sydney. Traditional Aboriginal culture may have been based on the land, but most aborigines now live in cities and towns in considerable deprivation. In Tharawal, they have doctors, GPs, registrars and the like, but they do a lot else. There are a range of community services including legal advice, help with housing and disability support. Subsidised fruit and vegetables are aimed at reducing the cost barriers to healthy eating.

I was shown around the Centre by two aboriginal women who have leadership roles there. On the same site that people visit their GP, services deal with the whole life course. Antenatal care was charming. Pregnant women are encouraged to celebrate pregnancy by making a plaster cast of their pregnant torso, and decorating it with aboriginal-inspired designs. Next in the life course the centre cares for children of various 
ages. The woman working with the two-year olds showed me the records she keeps to monitor early child development, one sheet for each child with 30 indicators of development. Well-evaluated programmes, such as Triple-P parenting are available for each family. The 'deadly homework club' supports older children.

Drugs, alcohol and domestic violence disrupt aboriginal families, as they do other families. I said to the aboriginal woman who was running this part of the centre: you must have the hardest job in this whole place. She said: I have the most rewarding job. She took me to an aboriginal painting on the wall, and told me that it was done by a man who came to her centre with the classic problems of drugs, alcohol and domestic violence. The centre helped him put his life back together. The painting was his gift, in gratitude.

The elders of the community have a place to gather and get involved. I was moved by a picture of older women on a march with a poster: Grannies against Removal. A psychologist at the centre deals with the psychological consequences of removal of children from their families. Such removal has a long and dark history. The 'stolen generation' describes Aboriginal children who were removed from their families with the aim of bringing them up "white", to relieve them of the aboriginal culture that was thought to be holding them back. It caused grief to both the children and their families, and was a dark episode in the long history of attacks on Aboriginal culture. Removal is still going on, I was told, where there is family disruption. But it, too, has large psychological costs on children and families.

\section{$\underline{\text { Advocacy }}$}

For an example of how we can get involved in advocacy see the last section.

\section{Networking}

As President of the World Medical Association it was expected that I attend certain meetings. My approach was to go only where I was invited to discuss my agenda on health equity through action on social determinants of health. Reviewing my diary for the few months before I took up the Presidency plus the actual year of my term, this selective approach limited me to visiting 25 countries. We are networking. There is a great deal of interest globally in social determinants of health, including among National Medical Associations. In some countries, this interest is being translated into action. Three examples:

The English city of Coventry has declared itself a Marmot city. The city government has taken my six recommendations, and is trying to apply them systematically. Other cities across the British Isles similarly have social determinants of health as a focus. We now have a collaboration on social determinants and health equity involving England, Scotland, Wales, Northern Ireland and the Republic of Ireland.

In Sweden, city and regional reviews of social determinants of health have been developing, starting with Malmo, extending to Linköping and Norrköping, Göteborg, and Östersund. There is now a national commission to examine social determinants of health.

PAHO, the Pan American Health Organisation has asked me to chair a new Commission on Equity and Health Inequalities in the Americas. The Commission covers all of the Americas, north, south and the 
Caribbean. The aim is to use the best available knowledge to influence policy and practice on social determinants of health and health equity. While in Washington for a Commission meeting, I noticed in The Mall this quote from Franklin D Roosevelt: "in these days of difficulty, we Americans everywhere must and shall choose the path of social justice... the path of faith, the path of hope, and the path of love toward our fellow man." I would add it is as timely now as it was when Roosevelt penned it.

\section{Advocacy}

I mentioned I delivered lectures in Australia, for the Australian broadcasting commission. To trail the lectures the $\mathrm{ABC}$ devoted an episode of their flagship current affairs programme to inequalities. On the programme, I gave examples of dramatic inequalities in power, money and resources, and pointed out that modest redistribution could have dramatic positive effects on social determinants of health and hence on health equity. Another panel member said: Redistribution! That's never going to happen. You're in fantasy land!

It was the next day when I went to Tharawal aboriginal community centre, and one of the doctor had a sign that said "Welcome to fantasy land". That sign inspired me to change the ending of my first lecture. I said that in the lectures that follow, I will deal with a fairer distribution of power, money and resources. But I've been told I'm in fantasy land. Martin Luther King rose in Washington, and declared "I have a dream, that on the red hills of Georgia, the sons of former slaves, and the sons of former slave-owners will be able to sit down together at the table of brotherhood". What if instead he rose and said, "I've been told I'm in fantasy land. We should accept the status quo". There would have been no civil rights act.

I invite you, join me in my fantasy land, and let's dream of a fairer world. 
Figure 1

UCL Institute of Health Equity

$\therefore \mathrm{C}$

Life expectancy and disability free life expectancy, males - based on 2011 Census

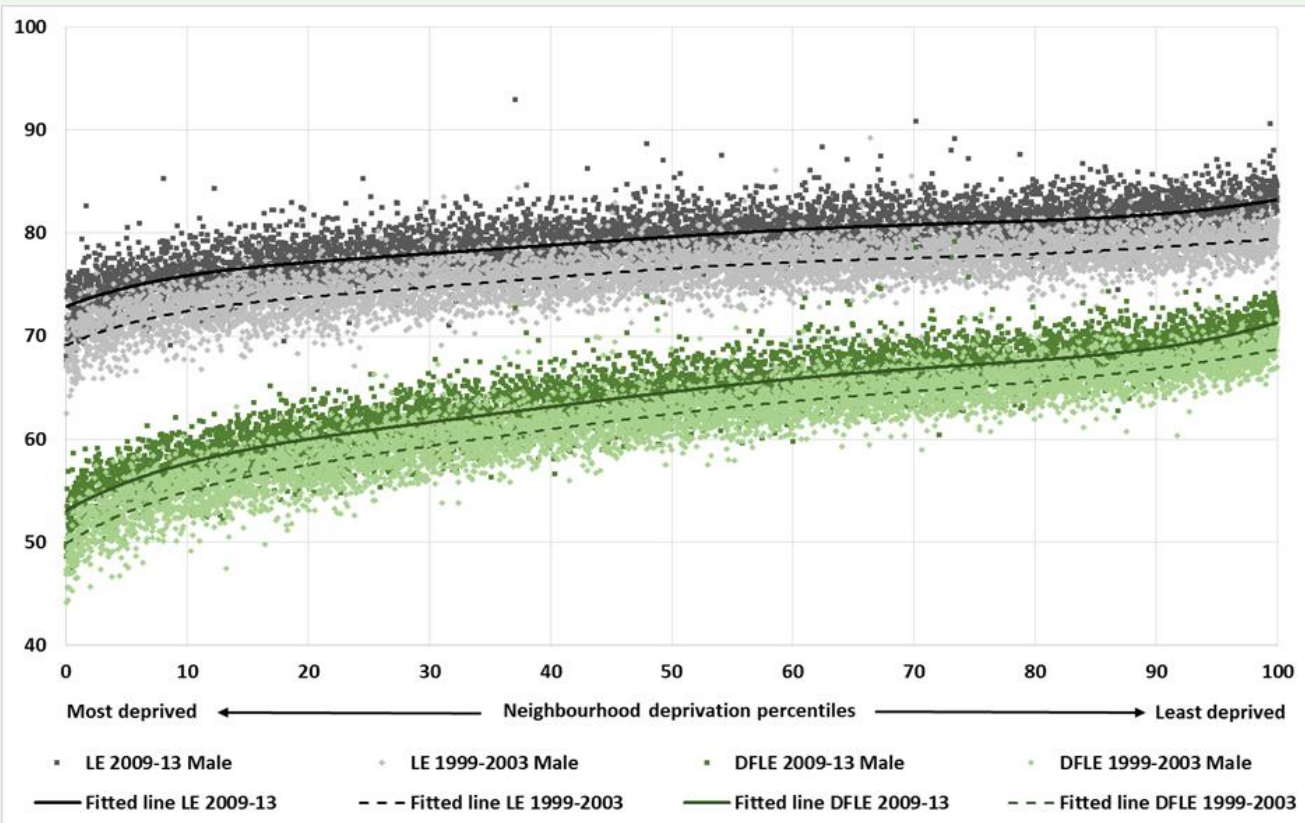

Life expectancy and disability-free life expectancy (DFLE) at birth, males by neighborhood deprivation, England, 19992003 and 2009-2013

Figure 2

$\overline{U C L}$ Institute of Health Equity

Life expectancy at age 25 by education, men

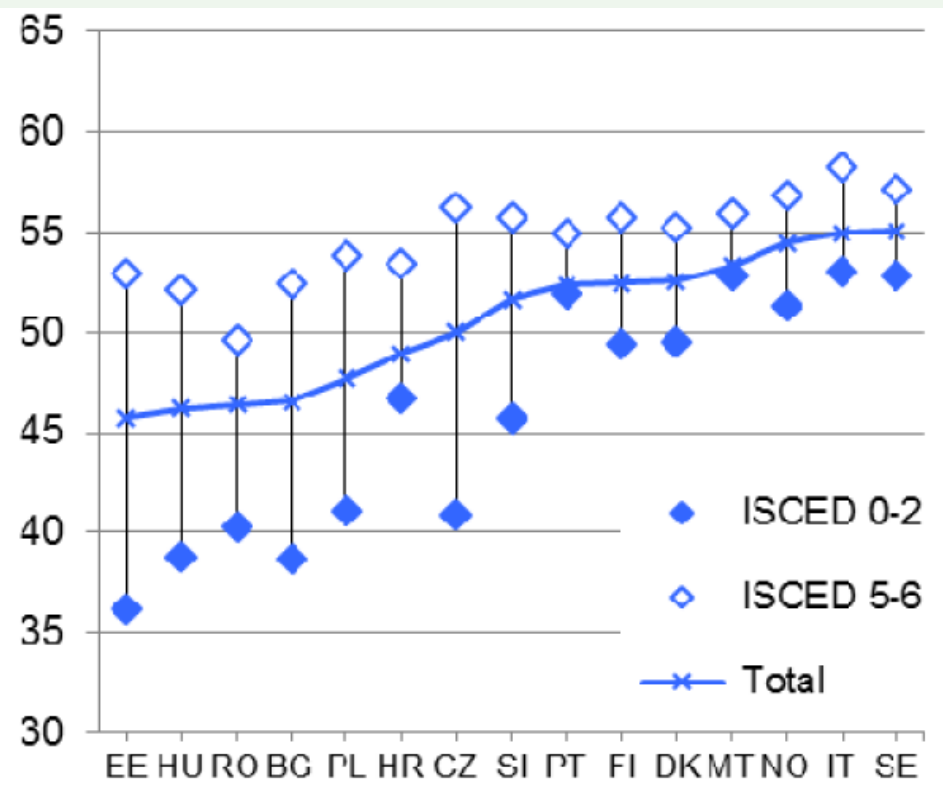

Source: Health inequalities in the EU 2013 
Figure 3

$\overline{\text { UCL Institute of Health Equity }}$

Inequalities in childhood obesity are increasing in England:

Obesity prevalence by deprivation decile 2006/7 to 2012/13

Children in Year 6 (aged 10-11 years)

$30 \%$

$\begin{array}{lllllll}\square 2006 / 07 & \square 2007 / 08 & \square 2008 / 09 & \square 2009 / 10 & \square 2010 / 11 & \text { 口2011/12 } & \text { 口2012/13 }\end{array}$

$25 \%$

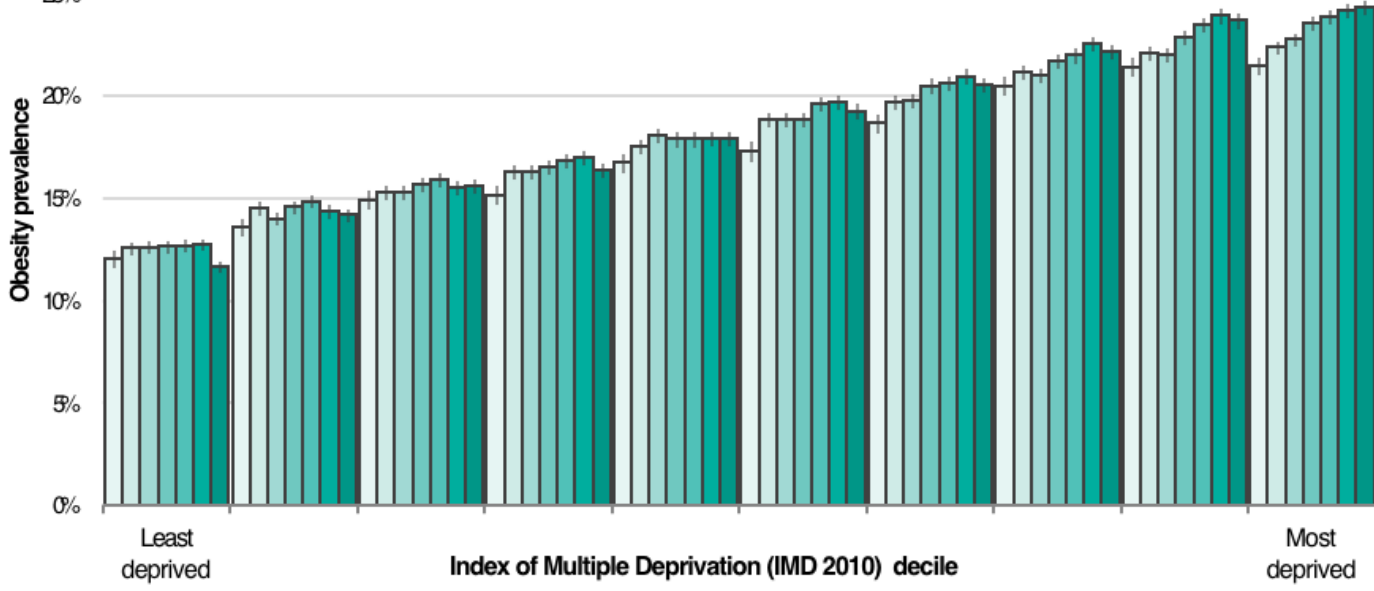

Child obesity: BMI $\geq 95^{\text {th }}$ centile of the UK90 growth reference

National Child Measurement Programme 2006/7 to2012/13

Figure 4

$\overline{U C L}$ Institute of Health Equity

Children achieving a good level of development at age five, local authorities 2011: England

\section{Good level \\ of development}

at age 5

$80^{\%}$

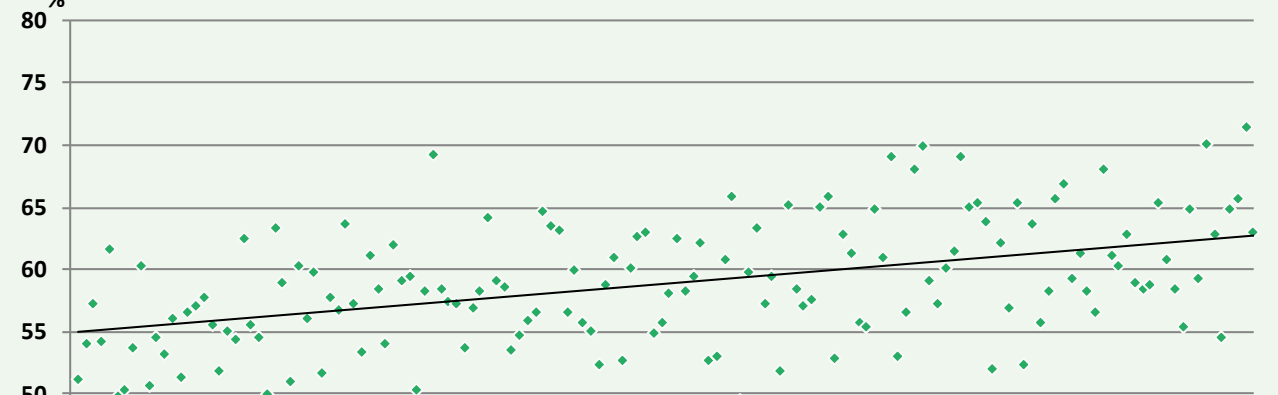

50

45

40

30 Local authority rank - based on Index of Multiple Deprivation 120

Source: LHO (2012) 
Figure 5

UCL Institute of Health Equity

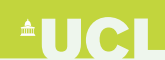

Level of development at end of reception

\begin{tabular}{|l|c|c|c|}
\hline \multirow{2}{*}{$\begin{array}{c}\text { England and selected local } \\
\text { authority areas }\end{array}$} & \multicolumn{3}{|c|}{ Level of development at age 5, 2013/14 } \\
\cline { 2 - 4 } & All pupils (\%) & FSM pupils (\%) & $\begin{array}{c}\text { Gap between all and } \\
\text { FSM pupils } \\
\text { (percentage point) }\end{array}$ \\
\hline England & 60.4 & 44.8 & 15.6 \\
\hline Hackney & 64.9 & 60.7 & 4.2 \\
\hline Bath and North East Somerset & 62.5 & 33 & 29.5 \\
\hline
\end{tabular}

1. Marmot M. The Health Gap. London: Bloomsbury; 2015.

2. Marmot M. Fair society, healthy lives : the Marmot review ; strategic review of health inequalities in England post-2010: [S.I.] : The Marmot Review; 2010.

3. Marmot MG, Rose G, Shipley M, Hamilton PJS. Employment grade and coronary heart disease in British civil servants. Journal of Epidemiology and Community Health. 1978;32:244-9.

4. Case A, Deaton, A. Rising morbidity and mortality in midlife among white non-Hispanic Americans in the 21st century. Proceedings of the National Academy of Sciences of the United States of America. 2015;112(49):15078-83.

5. Marmot M (Consortium Lead). Health inequalities in the EU - Final report of a consortium. 2013.

6. Macdonald L, Cummins S, MacIntyre S. Neighbourhood fast food environment and area deprivationsubstitution or concentration? Appetite. 2007;49(1):251-4.

7. Commission on the Social Determinants of Health. Closing the gap in a generation: health equity through action on the social determinants of health. Final report of the Commission on Social Determinants of Health. Geneva: World Health Organisation; 2008.

8. Siegrist J, Benach J, McKinght A, Goldblatt P, Muntaner C. Employment arrangements, work conditions and health inequalities: report on new evidence on health inequalitiy reduction, produced by Task group 2 for the Strategic Review of Health Inequalities post 2010. London:

http://www.ucl.ac.uk/gheg/marmotreview/consultation/Employment arrangements work conditions report 2009. 